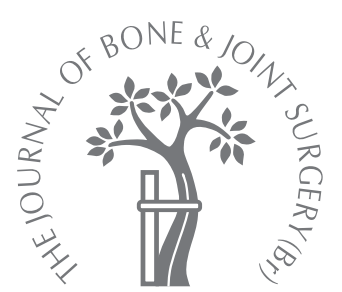

J. Oakley, J. H. Kuiper

From the Robert Jones and Agnes Hunt Orthopaedic Hospital, Oswestry, England and the Institute for Science and Technology in Medicine, Keele University, England

I. Jakley, MRCS Ed Specialist Registrar

J. H. Kuiper, PhD, Lecturer in Biomechanics

Robert Jones and Agnes Hunt Orthopaedic Hospital, Oswestry, Shropshire SY10 7AG, UK.

Correspondence should be sent to $\mathrm{Mr}$ J. Oakley; e-mail: Jeremy@

oakley31177.fsnet.co.uk

C2006 British Editorial Society of Bone and Joint Surgery doi:10.1302/0301-620X.88B6 $17278 \$ 2.00$

$J$ Bone Joint Surg [Br] 2006;88-B:828-31.

Received 6 October 2005;

Accepted after revision

5 January 2006

\title{
Factors affecting the cohesion of impaction bone graft
}

The role of bone-graft extenders in impaction revision surgery is becoming increasingly important. Tricalcium phosphate and hydroxyapatite have been shown to be both biocompatible and osteoconductive, yet many surgeons remain reluctant to use them. The difficulty in handling bone-graft extenders can be partly alleviated by using porous particles and adding clotted blood.

In an in vitro model we measured the cohesive properties of various impaction graft mixes. Several factors were evaluated including the use of pure bone graft compared with mixes with extender, washing the bone and the addition of clotted blood.

Our findings showed that pure allograft bone particles had significantly higher cohesion than when mixed with extender $(p<0.001)$. Washing had no effect on cohesion. The addition of clotted blood significantly increased the cohesion of both pure bone $(p<0.019)$ and mixes with pure bone and with porous graft extender $(p<0.044)$.

The use of morsellised bone allograft has already been proven to be successful in addressing the problem of bone defects in revision total hip replacement. ${ }^{1}$ However, there is increasing concern over the continued use of allograft because of high costs, limited supply ${ }^{2}$ and the risk of infection. ${ }^{3,4}$

There have been numerous studies that have examined the various aspects of producing particulate bone graft with an optimum composition. These include the size and grade of the bone particles, ${ }^{5-7}$ the effect of washing the bone graft, ${ }^{5,8,9}$ compaction itself, ${ }^{10,11}$ and the addition of bone-graft extenders. ${ }^{12-14}$ The role of the latter in impaction grafting revision surgery is becoming increasingly important. Tricalcium phosphate and hydroxyapatite (HA) have been shown to be biocompatible with bone and also to have osteoconductive properties. $^{15-17}$

Several studies have examined the use of bone-graft extenders in optimising the mechanical performance of morsellised bone graft and in altering early mechanical stability. $7,10,18$ A recent in vitro study by van Haaren et al, ${ }^{12}$ using human cadaver models of revision hip surgery, showed that a tricalcium phosphate/ HA allograft mix provided a higher initial mechanical stability compared with bone graft alone. However, it increased the risk of producing a fracture of the femur. ${ }^{12}$ Additional variables, identified as important for stability in laboratory studies, include the presence of clotted blood and bone cement. ${ }^{19}$

Many surgeons remain reluctant to use bone-graft extenders because of the different handling and mechanical properties compared with those of allograft. One particular problem in terms of handling is that during the impaction procedure, a large number of extender particles are removed each time the impactors are withdrawn. ${ }^{12}$ A possible explanation may be that the particles are less 'sticky' than bone graft. ${ }^{12}$ This 'stickiness' which binds particles together, is known as 'cohesion' in soil mechanics. $^{20}$ The presence of cohesion explains for instance, that it is possible to produce a cylinder from silts or clays, or compacted bone, and for this cylinder to remain standing for some time. This cannot be done with dry sand or ceramic particles, where the cylinder will collapse due to failure in shear. In silts, clays and compacted bone, some other factor contributes to shear strength, namely cohesion. No studies to date have directly measured the cohesion of graft mixes. Our aim was to determine which factors most influenced the cohesive properties of the graft mix.

\section{Materials and Methods}

We tested 16 groups of samples in total, with two samples per group. The groups were pure bone (washed and unwashed), pure graft extender (both solid and porous), and mixes of 
bone and extenders in 50/50 ratios. All of the groups were tested with and without, the addition of clotted blood.

Fresh-frozen femoral heads, harvested at primary total hip replacement and stored at $-80^{\circ} \mathrm{C}$, were morsellised using a bone mill (Noviomagus; SMT, Nijmegen, The Netherlands) to produce bone particles with a median diameter, by volume, of $0.5 \mathrm{~mm}$. This number was determined from $2 \mathrm{D}$ image analysis and denotes the diameter at which half the total particle volume is smaller. For samples requiring washed bone, particles were rinsed in a sieve under running tap water at $37^{\circ} \mathrm{C}$ for one minute.

Allogran-N (Biocomposites Ltd, Stoke-on-Trent, United Kingdom) $100 \%$ HA was used as the 'solid' bone-graft extender and Biosel (Depuy CMW, Blackpool, United Kingdom), with a $75 \% / 25 \% \mathrm{HA} /$ tricalcium phosphate mix as the 'porous' bone-graft extender.

Blood samples were withdrawn from the main author (JO) and stored in samples of $3.5 \mathrm{ml}$ in bottles with 120 $\mathrm{mmol} / \mathrm{l}$ trisodium citrate at room temperature to prevent clotting. ${ }^{21,22}$ Our clinical practice is to add $5 \mathrm{ml}$ of clotted blood to each $50 \mathrm{~g}$ of morsellised femoral head during impaction grafting procedures. ${ }^{19}$ We used samples of approximately $5 \mathrm{~g}$ and therefore used $0.5 \mathrm{ml}$ of blood per sample. In order to induce clotting, $60 \mu \mathrm{l}$ of $1 \mathrm{~mol}$ calcium chloride was added to each $0.5 \mathrm{ml}$ sample of blood, which was thoroughly mixed and then left to stand for six minutes in order to activate. ${ }^{21}$

The impacted graft was prepared in a cylindrical mould with an internal diameter of $16 \mathrm{~mm}$. The volume of the mould was such that $5 \mathrm{~g}$ of sample bone could be inserted before impaction. A $1 \mathrm{~kg}$ weight, comparable to an operative hammer, was dropped 20 times from a height of $50 \mathrm{~mm}$ on a piston to compact the bone. The height of all the samples was measured before and after impaction.

To determine the cohesion of the samples, which equals their shear strength at zero normal stress, we used the unconfined compression test. ${ }^{23}$ This is a common method for determining the cohesion of soil samples. ${ }^{20}$ It makes use of the fact that the maximum shear stress in a sample loaded by compression equals half of the applied compressive stress. ${ }^{20}$ Before the test, the mould was split lengthwise, so that the samples could be removed carefully. This left cylindrically-shaped specimens that were transferred to a $5 \mathrm{KN}$ servohydraulic testing machine (ESH Testing Ltd, Brierley Hill, United Kingdom). The specimens were loaded at a strain rate of $2.5 \%$ of the initial sample height per minute, to a maximum of $15 \%$ of sample height or until failure was achieved. Stress-strain diagrams were then compiled from the results and from these, the compressive strength at failure or at $15 \%$ strain was determined (Fig. 1). The sample size, loading rate and definition of failure were chosen according to an international standard. ${ }^{23}$ The cohesion or shear strength at zero total normal stress for each sample was then calculated as half the compressive strength. ${ }^{20}$

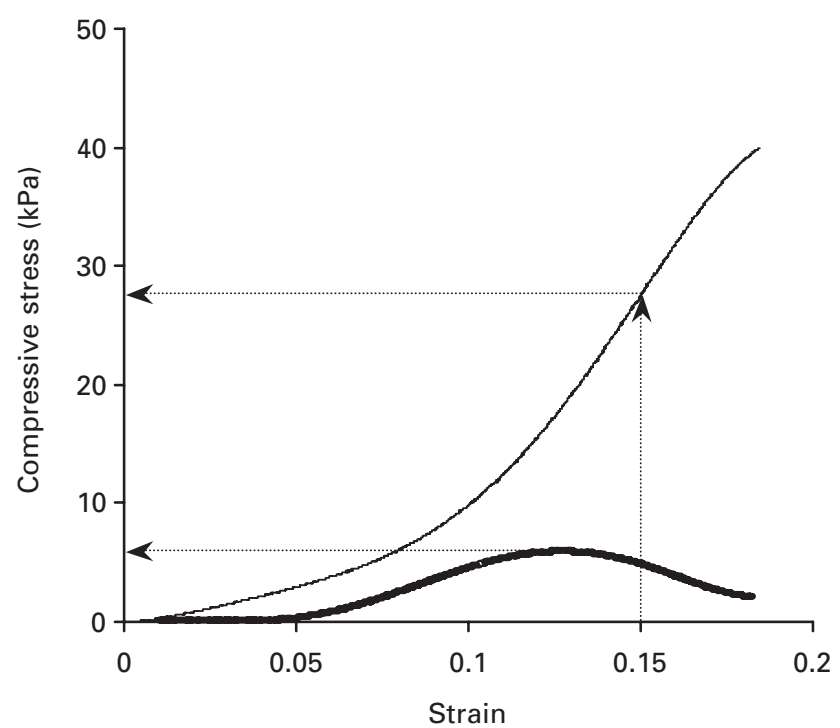

Fig. 1

Stress-strain diagram of unwashed bone and a 50/50 mixture of unwashed bone plus non-porous particles, loaded in unconfined compression. The arrows show the determination of compressive strength for samples failing below a strain of $15 \%$ (thick curve and arrow) and above a strain of $15 \%$ (thin curve and arrow).

Statistical analysis. A general linear model was used to analyse differences in mean cohesion, with percentage of bone, type of graft extender, the addition of clotted blood, and washing of the bone graft as independent factors. We analysed the effects of each independent factor separately and whether the effect of adding clotted blood depended on the type of extender or on the percentage of bone present.

A probability of $\mathrm{p}=0.05$ was assumed to indicate statistical significance. The cohesion-values needed to be square root-transformed in order to ensure equal variances, a prerequisite for linear models. All results were given as the mean and SEM after back transformation. All statistical analyses were performed using Systat 11 (Systat Software Inc., Richmond, California).

\section{Results}

Cylindrical specimens that did not collapse and were suitable for unconfined compression testing could be produced for all of the experimental groups which included morsellised bone. However, for the experimental groups based on extender alone we could only produce a single specimen that did not collapse: a porous extender with clotted blood. In all cases where it was impossible to produce a noncollapsing cylinder, a cohesion value of zero was assumed (Table I). None of the specimens based on pure bone failed during unconfined compression testing. The cohesion values for these specimens were therefore based on the compressive stress at $15 \%$ strain (Table I). The other specimens failed before a strain of $15 \%$ was reached (Table I). 
Table I. The mean cohesion for each separate experimental group

\begin{tabular}{lllll}
\hline Bone (\%) & Extender type & Clotted blood & Washing & Cohesion (kPa) \\
\hline 100 & - & No & No & 11.8 \\
100 & - & No & Yes & 12.1 \\
100 & - & Yes & No & 20.2 \\
100 & - & Yes & Yes & 27.2 \\
& & & & \\
50 & Solid & No & No & 1.4 \\
50 & Solid & No & Yes & 0.5 \\
50 & Solid & Yes & No & 0.2 \\
50 & Solid & Yes & Yes & 1.1 \\
50 & Porous & No & No & 2.1 \\
50 & Porous & No & Yes & 5.0 \\
50 & Porous & Yes & No & 10.4 \\
50 & Porous & Yes & Yes & 10.8 \\
& & & & \\
0 & Solid & No & - & 0.0 \\
0 & Porous & No & - & 0.0 \\
0 & Solid & Yes & - & 0.0 \\
0 & Porous & Yes & - & 0.0 \\
\hline
\end{tabular}

The percentage of bone had a strong influence on cohesion (Fig. 2). On average, halving the amount of bone resulted in a cohesion of only $18 \%$ of pure bone, and leaving all bone out left only $1 \%$. This influence was highly significant and had a linear $(\mathrm{p}<0.001)$ and a quadratic $(\mathrm{p}=$ 0.007 ) component. The addition of clotted blood approximately doubled the cohesion of the samples (Fig. 2), a highly significant effect $(\mathrm{p}=0.004)$.

When no clotted blood was present, no difference in cohesion was found between the two types of extender (Fig. $3)$. Adding clotted blood tripled the cohesion of samples with a porous extender, but had no effect on samples with a solid extender (Fig. 3). This interaction effect between the type of extender and the addition of blood was significant

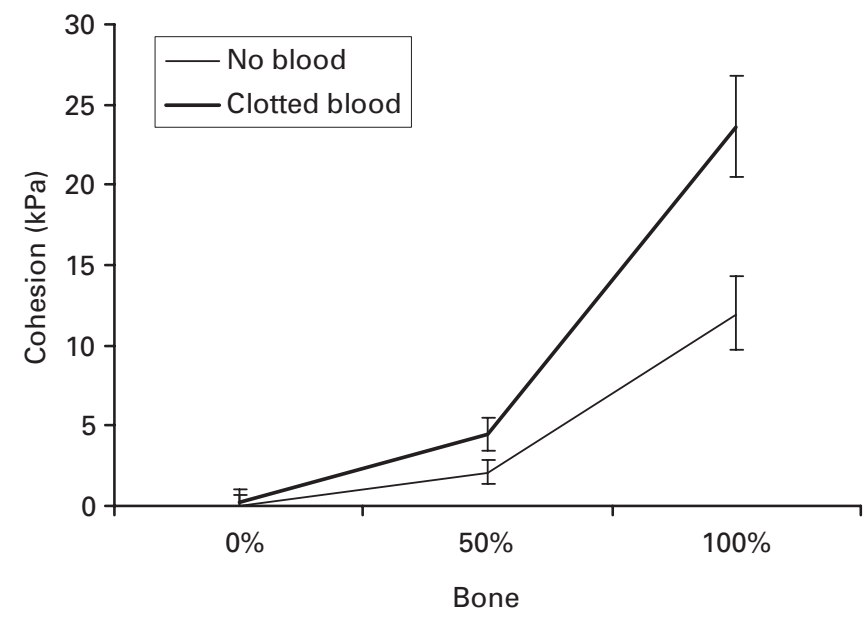

Fig. 2

Graph showing cohesion (mean and SEM) as a function of a percentage of bone, with or without the addition of clotted blood. $(\mathrm{p}=0.044)$. Washing did not significantly affect cohesion $(\mathrm{p}=0.30)$.

\section{Discussion}

Our aim was to identify the factors which influenced the cohesion of graft materials, as this directly affects the handling properties. We have shown that pure allograft bone particles have significantly higher cohesion than when mixed with graft extender, whether it is solid or porous. Using pure graft extender without allograft bone produced no cohesion. This suggested that it would not be suitable for clinical practice.

Although it has been shown that washing bone chips to remove fat can increase the stability of an acetabular component, ${ }^{9}$ we found that it had no significant effect on the cohesion of the particles in any of the mixes. Results from previous studies have suggested that rinsing removes both beneficial and harmful factors. ${ }^{1}$ Removing the fat by rinsing has been shown to significantly increase the initial stability of an implant and the force required to displace a grafted implant. ${ }^{10,24}$ However, for autograft the net effect was probably still negative since beneficial growth factors and cytokines were also removed. In terms of handling of the graft, washing had no effect. The very fact that washing did not affect our results suggests that cohesion between bone particles is not caused by fat or marrow binding the particles. We hypothesise that compacting cancellous bone particles produces a physical interlock between the particles, probably by plastically deforming and entangling the trabecular struts. Such plastic deformation and entangling will be possible for cancellous bone, because it is a composite of collagen fibres and ceramic, making it relatively plastic. It will, however, be impossible for graft extenders, even porous ones, because they are purely ceramic and therefore, brittle.

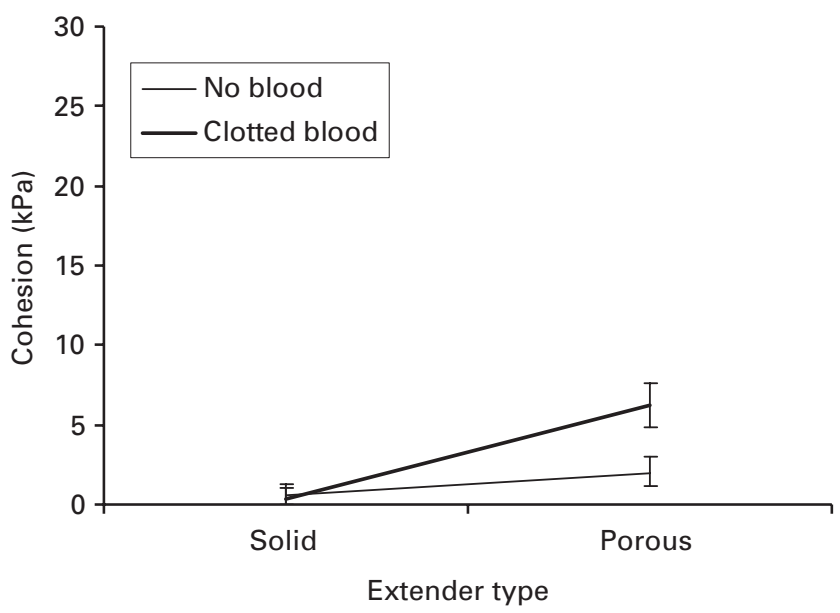

Fig. 3

Graph showing cohesion (mean and SEM) as a function of type of extender, with or without the addition of clotted blood. 
In general, the addition of clotted blood significantly increased the cohesion of the pure bone graft samples and those with a 50/50 mix of bone graft and porous graft extender. For samples with a 50/50 mix of bone graft and solid graft extender, blood had no significant influence on cohesion. We believe this finding may be due to the larger surface area of the porous extender available for blood to adhere to. Another possible explanation is that blood may penetrate into the pores of the extender before clotting, thus allowing a physical connection to form.

From the perspective of transmission of disease, elimination of the use of allograft bone would be ideal. However, we have shown that using $100 \%$ graft extender does not appear to be a viable option. Previous studies have shown that from a biomechanical and clinical point of view, mixtures of bone with HA or tricalcium phosphate/HA form viable graft extenders for use in impaction grafting of the acetabulum and the femur. ${ }^{12,25}$ However, such mixes need to be handled differently from pure allograft bone. One particular problem mentioned in the literature is that during the impaction procedure a large number of extender particles are removed each time the impactors are withdrawn. Our work suggests that this may be due to the much lower cohesion of compacted bone/extender mixtures, compared to that of compacted pure bone particles. If this problem occurs and the graft is porous, then our results suggest adding clotted blood may alleviate it.

The strength of our experimental design was that it examined a number of variables affecting the cohesion of impaction graft mixes. However, we recognise that cohesion is not the only factor affecting graft handling and that further research is required. In addition, it should be realised that properties other than handling characteristics may be more important when choosing a particular extender.

No benefits in any form have been received or will be received from a commercial party related directly or indirectly to the subject of this article.

\section{References}

1. Toms AD, Barker RL, Jones RS, Kuiper JH. Impaction bone-grafting in revision joint replacement surgery. J Bone Joint Surg [Am] 2004;86-A:2050-60.

2. Galea G, Kopman D, Graham BJM. Supply and demand of bone allograft for revision hip surgery in Scotland. J Bone Joint Surg [Br] 1998;80-B:595-9.
3. Conrad EU, Gretch DR, Obermeyer KR, et al. Transmission of the hepatitis ${ }^{+} \mathrm{C}$ virus by tissue transplantation. J Bone Joint Surg [Am]1995;77-A:214-24.

4. Sugihara S, van Ginkel AD, Jiya TU, et al. Histopathology of retrieved allografts of the femoral head. J Bone Joint Surg [Br] 1999;81-B:336-41.

5. Dunlop DG, Brewster NT, Madabhushi SPG, et al. Techniques to improve the shear strength of impacted bone graft. J Bone Joint Surg [Am] 2003;85-A:639-46.

6. Eldridge JDJ, Hubble MJW, Nelson K, Smith EJ, Learmonth ID. The effects of bone chip size on initial stability following femoral impaction grafting. J Bone Joint Surg [Br] 1997;79-B(Suppl 3):364.

7. Kuiper JH, Merry JC, Cheah K, Richardson JB. Graft composition influences early mechanical stability in impaction grafting. Trans EORS 1996;6:45.

8. Voor MJ, Nawab A, Malkani AL, Ullrich CR. Mechanical properties of compacted morsellised cancellous bone graft using one-dimensional consolidation testing. J Biomech 2000;33:1683-8.

9. Ullmark G. Bigger size and defatting of bone chips will increase cup stability. Arch Orthop Trauma Surg 2000;120:445-7

10. Kuiper JH, Soliman A, Cheah K, Richardson JB. Stability of impaction-grafted hip and knee prostheses: surgical technique, implant design and graft compaction. In: Delloye C, Bannister G, eds. Impaction bone grafting in revision arthroplasty. New York: Marcel Dekker, 2004:75-94.

11. Ornstein E, Atroshi I, Franzen H, et al. Early complications after one hundred and forty-four consecutive hip revisions with impacted morsellized allograft and cement. $J$ Bone Joint Surg [Am] 2002;84-A:1323-8.

12. van Haaren EH, Smit TH, Phipps $K$, et al. Tricalcium-phosphate and hydroxyapatite bonegraft extender for use in impaction grafting revision surgery: an in vitro study on human femora. J Bone Joint Surg [Br] 2005;87-B:267-71.

13. Blom AW, Grimm B, Miles AW, Cunningham JL, Learmonth ID. Subsidence in impaction grafting: the effect of adding a bone graft extender to bone. Proc Inst Mech Eng [H] 2002;216:265-70

14. Grimm B, Miles AW, Turner IG. Optimizing a hydroxyapatite/tricalcium-phosphate ceramic as a bone graft extender for impaction grafting. J Mat Sciences 2001;12:929-34.

15. Gatti AM, Zaffe D, Poli GP. Behaviour of tricalcium phosphate and hydroxyapatite granules in sheep bone defects. Biomaterials 1990;11:513-17.

16. Kitsugi T, Yamamro T, Nakamura T, et al. Four calcium phosphate ceramics as bone substitutes for non-weight-bearing. Biomaterials 1993;14:216-24.

17. Zambonin G, Grano M. Biomaterials in orthopaedic surgery: effects of different hydroxyapatites and demineralised bone matrix on proliferation rate and bone matrix synthesis by human osteoblasts. Biomaterials 1995;16:397-402.

18. Brewster NT, Gillespie WJ, Howie CR, et al. Mechanical considerations in impaction bone grafting. J Bone Joint Surg [Br] 1999;81-B:118-24.

19. Smith EJ, Richardson JB, Learmonth ID, et al. The initial stability of femoral impaction grafting. Hip International 1996;6:166-72

20. Smith GN. Elements of soil mechanics. Sixth ed. Oxford: Blackwell Science, 1995

21. Camenzind V, Bombeli T, Seifert B, et al. Citrate storage affects thrombelastograph analysis. Anesthesiology 2000;92:1242-9.

22. Dacie JV, Lewis SM. Practical haematology. Eighth Edition. Edinburgh: Churchill Livingstone Publications 1995:1-7.

23. ASTM D2166-00. Standard test method for unconfined compressive strength of cohesive soil. American Society for Testing and Materials 2000.

24. Hostner J, Hultmark P, Karrholm J, Malchau H, Tveit M. Impaction technique and graft treatment in revisions of the femoral component: laboratory studies and clinical evaluation. J Arthroplasty 2001;16:76-82.

25. Gokhale S, Soliman A, Dantas JP, et al. Variables affecting intital stability of impaction grafting for hip revision. Clin Orthop 2005;432:174-80. 